\title{
Nanosphere of Semicrystalline Polyaniline Powder: An Effective, Versatile, and Reusable Catalyst for Hantzsch Reaction
}

\author{
Ravi Bolagam, Rajender Boddula, and Palaniappan Srinivasan \\ Polymers \& Functional Materials Division, CSIR-Indian Institute of Chemical Technology, Hyderabad 500 007, India \\ Correspondence should be addressed to Palaniappan Srinivasan; palani74@rediffmail.com
}

Received 31 May 2014; Accepted 22 August 2014; Published 15 September 2014

Academic Editor: Vijay Bokade

Copyright (C) 2014 Ravi Bolagam et al. This is an open access article distributed under the Creative Commons Attribution License, which permits unrestricted use, distribution, and reproduction in any medium, provided the original work is properly cited.

\begin{abstract}
Polyaniline salt containing 1-hydroxyethane-1,1-diphosphonic acid with nanosphere morphology in semicrystalline powder form was successfully synthesized by interfacial polymerization pathway and demonstrated as polymer based acid catalyzed in the synthesis of 1,4-dihydropyridines and polyhydroquinoline derivatives. This catalyst promotes the reaction under solvent free condition in excellent yield in $10 \mathrm{~min}$ with recyclability. The advantages of this methodology are the easy synthesis of polymer containing acid group catalyst in powder form having easily handlable, efficient, versatile, and reusable nature.
\end{abstract}

\section{Introduction}

Multicomponent reactions (MCRs) are important for generating high levels of diversity because they allow more than two building blocks to be combined in a practical, time saving, one-pot operation to give rise to complex structures by simultaneous formation of two or more bonds. MCRs are extremely convergent, producing a remarkably high increase of molecular complexity in just one step [1, 2]. 1,4-Dihydropyridines are well known as calcium channel modulators and have emerged as one of the most important classes of drugs for the treatment of cardiovascular diseases. Cardiovascular agents such as nifedipine, nicardipine, amlodipine, and other related derivatives are dihydropyridyl compounds, effective in treatment of hypertension $[3,4] .1,4-$ Dihydropyridine derivatives possess a variety of biological activities such as vasodilator, bronchodilator, antiatherosclerotic, antitumor, geroprotective, hepatoprotective, and antidiabetic activity $[5,6]$. Thus, the synthesis of this heterocyclic nucleus is of much importance.

In 1882, Hantzsch reported first synthesis of symmetrically substituted 1,4-dihydropyridines by the one-pot, fourcomponent condensation of two molecules of ethyl acetoacetate, aromatic aldehyde, and ammonia [7]. The standard Hantzsch procedure does not need the intervention of any additive or reagent and the reaction was originally conducted either in acetic acid or at reflux in alcohol for rather long periods, resulting in lower modest yields of condensation products. Replacement of ammonia by ammonium acetate allowed the efficient synthesis of Hantzsch compounds in aqueous medium as well as under solvent free conditions $[8,9]$.

Realizing the importance of polyhydroquinoline derivatives in the synthesis of various drug sources, numerous methods have been reported such as conventional heating $[10$, 11], various catalysts such as L-proline [12], ceric ammonium nitrate (CAN) [13], silica perchloric acid $\left(\mathrm{HClO}_{4}-\mathrm{SiO}_{2}\right)$ [14], nickel nanoparticle [15], $\mathrm{FeF}_{3}[16], \mathrm{K}_{7}\left[\mathrm{PW}_{11} \mathrm{CoO}_{40}\right]$ [17], solar heat [18], bakers' yeast [19], and nafion- $\mathrm{H}$ [20]. However, these methods suffer from several disadvantages such as moisture sensitive, highly toxic, unpleasant experimental procedure, expensive reagents, use of larger quantities of volatile organic solvents, long reaction times, low yields, and harsh reaction conditions. Therefore, it is necessary to develop an efficient and versatile method for the synthesis of these compounds. Therefore, the search for a better catalyst for the synthesis of polyhydroquinoline derivatives using less hazardous solvents or solvent free conditions is of prime importance. Synthesis of nanomaterial [21-23] is also significant in catalyst application. A mild and efficient catalyst for the synthesis of polyhydroquinoline is very desirable. It would be significantly safe, cheap, nontoxic, 
and environmentally friendly compared to organic solvents. Hence, there is still great demand for a new catalytic system with high efficiency and low catalytic loading.

In this paper work, novel polyaniline salt containing 1hydroxyethane-1,1-diphosphonic acid was successfully synthesized by interfacial polymerization pathway and is well characterized. This PANI-HEDP is used as an efficient and reusable polymer based solid acid catalyst in the Hantzsch reaction.

\section{Experimental}

PANI-HEDP salt was prepared by interfacial polymerization pathway, characterized and used as a polymer based solid acid catalyst in Hantzsch reaction.

2.1. Instruments and Characterization. Powder of PANIHEDP was pressed into a disk of $13 \mathrm{~mm}$ diameter and about $1.5 \mathrm{~mm}$ thickness under a pressure of $120 \mathrm{Kg} / \mathrm{cm}^{2}$. Resistance of the pellet was measured by four-probe method using 6220 constant current source and 2182A voltmeter (Keithley, Cleveland, Ohio, USA). Pellet density was measured from mass per unit volume of the pressed pellet. FTIR spectra of polymer samples were registered on a FTIR spectrometer (Thermo Nicolet Nexus 670, USA) using the $\mathrm{KBr}$ pressed pellet technique. X-ray diffraction profiles for polymer powders were obtained on a Siemens/D-500 $\mathrm{X}$-ray diffractometer, USA, using $\mathrm{Cu} \mathrm{K} \alpha$ radiation, with scan speed of $0.045^{\circ} / \mathrm{min}$. Morphological studies of PANI salt powders were performed using Hitachi 3000N, Tokyo, Japan, scanning electron microscope operating at $10 \mathrm{kV}$. The sample was mounted on a double-sided adhesive carbon disk and sputter-coated with a thin layer of gold to prevent sample from possible charging. The energy-dispersive Xray (EDAX) spectroscopy was analysed with an EDAX detector (Oxford LINK-ISIS 300) with Jest microscope. ${ }^{1} \mathrm{H}$ NMR spectra of all the products in DMSO-d6 with TMS as internal standard were taken using Avance-500/Inova400 instruments. Thermogravimetric analyses of polymer samples were carried out using TA Instruments (TGA Q500 V20.8, USA) up to $700^{\circ} \mathrm{C}$ at a heating rate of $10^{\circ} \mathrm{C}$ per minute.

\subsection{Synthesis of PANI-HEDP Salt by Interfacial Polymer-} ization Pathway. Aniline $(1 \mathrm{~mL}), 60 \%$ aqueous solution of 1-hydroxyethane-1,1-diphosphonic acid $(5 \mathrm{~mL})$, and sodium lauryl sulfate $(1 \mathrm{~g})$ were dissolved in $70 \mathrm{~mL}$ distilled water taken in $250 \mathrm{~mL}$ beaker. Benzoyl peroxide ( $3 \mathrm{~g}$ ) was dissolved in $30 \mathrm{~mL}$ of toluene. This organic solution was added drop by drop to aqueous solution through the sides of the beaker for a period of $15 \mathrm{~min}$ without disturbing the reaction mixture. The reaction was carried out for $24 \mathrm{~h}$ without stirring the reaction mixture. Two layers were separated at the end of the reaction; organic layer was removed from the aqueous layer and poured into acetone. The precipitate was filtered and washed with an ample amount of water finally with $250 \mathrm{~mL}$ of acetone. The powder sample was dried at $50^{\circ} \mathrm{C}$ till a constant weight.

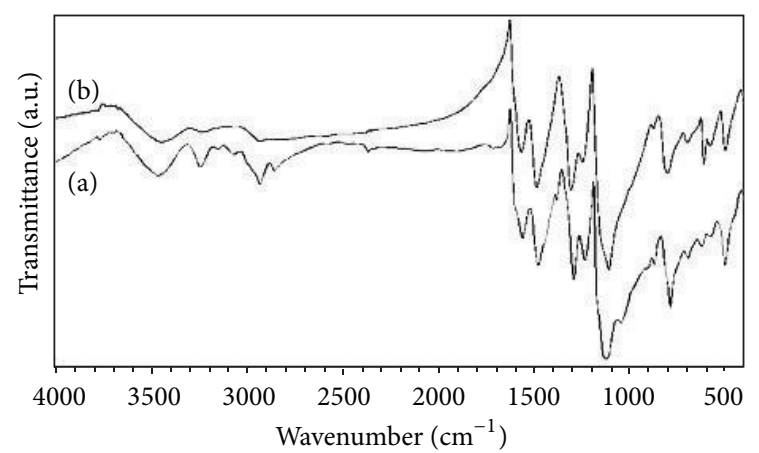

FIGURE 1: Infrared spectra of (a) PANI-HEDP and (b) recycled PANI-HEDP.

2.3. Synthesis of 1,4-Dihydropyridines Using PANI-HEDP Catalyst. A mixture of aldehydes $(2 \mathrm{mmol})$, ethyl acetoacetate ( $4 \mathrm{mmol})$, ammonium acetate $(3 \mathrm{mmol})$, and PANI-HEDP catalyst ( $40 \mathrm{mg} ; 7 \mathrm{wt} \%$ with respect to aldehyde) was stirred at ambient temperature for a particular period of time and monitored with TLC. After completion of reaction, ethyl acetate was added into the reaction mixture and filtered in order to separate the catalyst. Ethyl acetate was washed with water and evaporated ethyl acetate solvent to get the crude product. Pure product was obtained from recrystallization from ethanol. The separated catalyst was washed with acetone, dried in an oven at $50^{\circ} \mathrm{C}$ for $10 \mathrm{~min}$, and reused.

2.4. Synthesis of Polyhydroquinolines Using PANI-HEDP Catalyst. Aldehydes $(2 \mathrm{mmol})$, dimedone $(2 \mathrm{mmol})$, ethyl acetoacetate $(2 \mathrm{mmol})$, ammonium acetate $(3 \mathrm{mmol})$, and PANIHEDP catalyst ( $40 \mathrm{mg} ; 7 \mathrm{wt} \%$ with respect to aldehyde) were stirred at ambient temperature for a particular period of time and monitored with TLC. Isolate the product by using the above procedure.

\section{Results and Discussion}

3.1. Preparation and Characterization of Polyaniline Catalyst. Aniline was oxidized to polyaniline salt by interfacial polymerization pathway (Scheme 1). Aniline, 1-hydroxyethane1,1-diphosphonic acid (HEDP), and sodium lauryl sulfate were taken in water. Benzoyl peroxide was dissolved in organic solvent. Organic layer was added to aqueous layer through the side of the beaker without disturbing the reaction mixture. The reaction was carried at ambient temperature without stirring. The polymerization reaction was started at the interface between the aqueous and organic layer. PANIHEDP was obtained in $1.05 \mathrm{~g}$ yield (with respect to $1 \mathrm{~mL}$ of aniline used) with pellet density $\left(1.32 \mathrm{~g} / \mathrm{cm}^{3}\right)$.

3.2. Infrared Spectra of PANI-HEDP. The infrared spectrum of PANI-HEDP is shown in Figure 1(a) and it shows major characteristic peaks of polyaniline salt at $3450 \mathrm{~cm}^{-1}(\mathrm{~N}-$ $\mathrm{H}$ str.), $3230 \mathrm{~cm}^{-1}\left(\mathrm{NH}^{+}\right.$indicative of doping), $1565 \mathrm{~cm}^{-1}$ ( $\mathrm{C}=\mathrm{C}$ str., quinonoid ring), $1480 \mathrm{~cm}^{-1}$ ( $\mathrm{C}=\mathrm{C}$ str., benzenoid ring), $1300 \mathrm{~cm}^{-1}$ (C-N str., quinonoid ring), $1240 \mathrm{~cm}^{-1}$ (C-N 


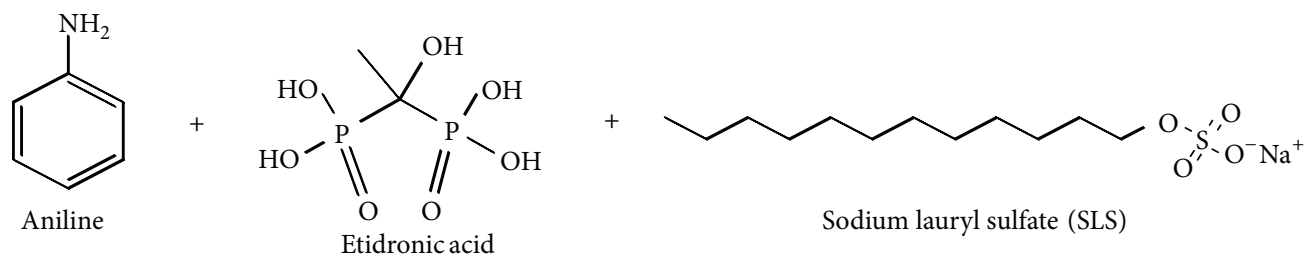

(or)

1-Hydroxyethane-1,1-diphosphonic acid (HEDP)

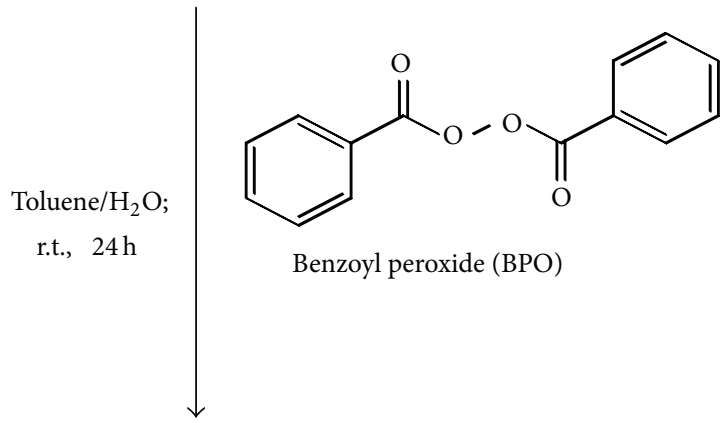

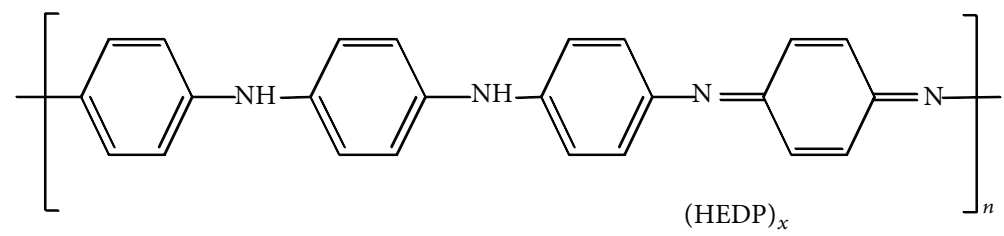

(PANI-HEDP)

SCHEME 1: Synthesis of PANI-HEDP catalyst by interfacial polymerization pathway.

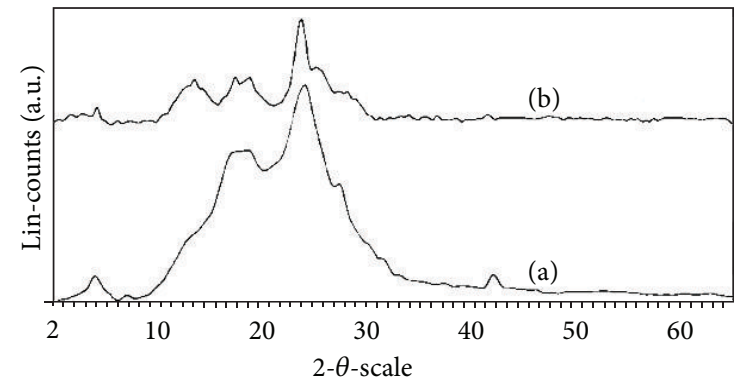

Figure 2: X-ray diffraction patterns of (a) PANI-HEDP and (b) recycled PANI-HEDP.

str., benzenoid ring), $1130 \mathrm{~cm}^{-1}$ (electronic vibrational band), and $800 \mathrm{~cm}^{-1}$ (1,4-disubstituted benzene). In addition to the normal peaks of polyaniline salt, PANI-HEDP shows peaks at 2925 and $2850 \mathrm{~cm}^{-1}$ due to $\mathrm{C}-\mathrm{H}$ structure of HEDP and 1655 and $1040 \mathrm{~cm}^{-1}$ due to $\mathrm{PO}_{3} \mathrm{H}$ group of HEDP, which indicates the presence of HEDP as dopant on polyaniline. Infrared spectrum of recycled PANI-HEDP (Figure 1(b)) shows peaks similar to that of the as-synthesized PANIHEDP (Figure 1(a)).

3.3. XRD Patterns of Polyaniline. X-ray diffraction profiles registered for PANI-HEDP (Figure 2(a)) show three broad peaks around $2 \theta=6,20,25$, and $29^{\circ}$ with corresponding $d$-spacing of $14.8,4.5,3.5$, and 3.1 , respectively, indicating semicrystalline nature. These peaks are matching with reported X-ray pattern for polyaniline salt [24]. X-ray diffraction pattern of recycled PANI-HEDP salt (Figure 2(b)) shows peaks similar to that of PANI-HEDP (Figure 2(a)).

3.4. FE-SEM and EDAX of PANI-HEDP. Morphological structure of PANI-HEDP shows nanospheres with diameter ranging from 80 to $140 \mathrm{~nm}$ size (Figure 3(a)). Recycled PANIHEDP catalyst also shows nano spheres morphology with diameter ranging from 100 to $140 \mathrm{~nm}$ size (Figure 3(b)). Energy-dispersive X-ray spectroscopy of PANI-HEDP indicates the presence of elements such as carbon, nitrogen, and phosphorous. The qualitative values are carbon $(25 \%)$, nitrogen $(20 \%)$, oxygen (41\%), and phosphorous (14\%). The presence of phosphorous element indicates that polyaniline 


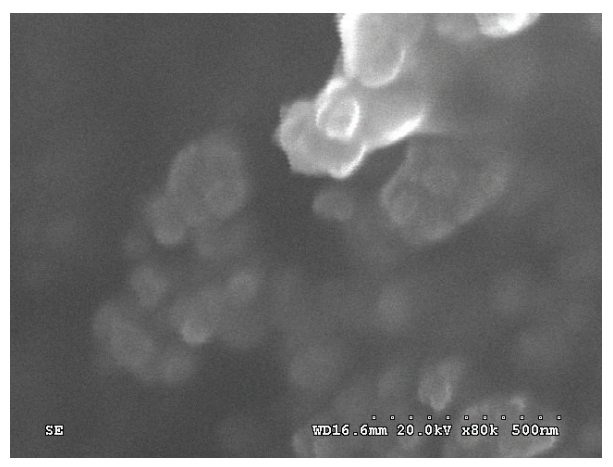

(a)

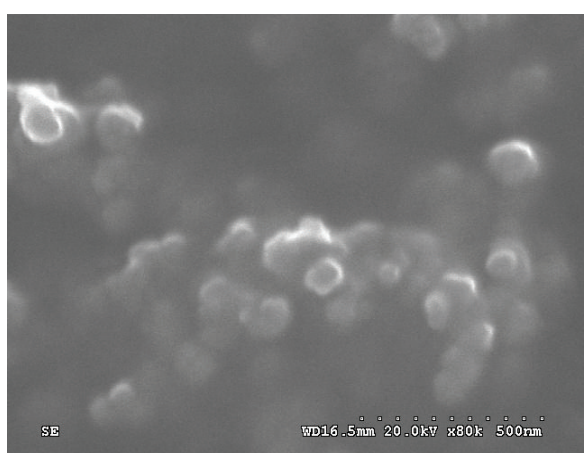

(b)

FIgure 3: FE-SEM pictures of (a) PANI-HEDP and (b) recycled PANI-HEDP.

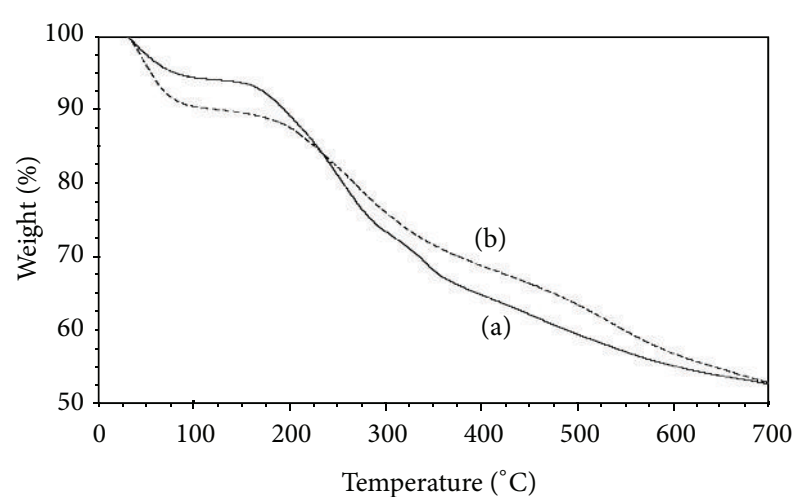

FIGURE 4: TGA thermograms of (a) PANI-HEDP and (b) recycled PANI-HEDP.

salt contains HEDP as dopant. EDAX of recycled PANIHEDP salt shows elements of carbon (30\%), nitrogen (21\%), oxygen (36\%), and phosphorous (13\%).

\subsection{Thermogravimetry of PANI-HEDP. TGA thermogram} of PANI-HEDP is shown in Figure 4(a). TGA thermogram shows small weight loss behaviour up to $110^{\circ} \mathrm{C}$ and the sample is stable up to $160^{\circ} \mathrm{C}$ and then undergoes degradation of the polymer chain. Similar weight loss behaviour was observed for the recycled PANI-HEDP sample, which is stable up to $170^{\circ} \mathrm{C}$ (Figure 4(b)).

Interfacial polymerization of aniline gives polyaniline salt containing protic acid group in excellent yield with nanospheres morphology and semicrystalline nature having stability up to $160^{\circ} \mathrm{C}$. By considering the presence of protic acid on polyaniline, we used polyaniline salt as catalyst in symmetrical and unsymmetrical Hantzsch reaction and the results are discussed here.

3.6. Synthesis of Hantzsch Reaction Using PANI-HEDP Catalyst. In continuation of our investigation on the use of new catalysts as conjugated conducting polymers as reusable catalysts for carrying out chemical transformations [25], in
TABLE 1: Synthesis of 1,4-dihydropyridine by PANI-HEDP at ambient temperature in different medium ${ }^{\mathrm{a}}$.

\begin{tabular}{lccc}
\hline Entry & Solvent & Time $(\mathrm{h})$ & Isolated yield (\%) \\
\hline 1 & $\mathrm{H}_{2} \mathrm{O}$ & 4 & 34 \\
2 & $\mathrm{CH}_{3} \mathrm{CN}$ & 2 & 88 \\
3 & $\mathrm{CH}_{2} \mathrm{Cl}_{2}$ & 2 & 60 \\
4 & No solvent & 0.16 & 93 \\
\hline
\end{tabular}

${ }^{a}$ Ethyl acetoacetate $(4 \mathrm{mmol})$, 4-chlorobenzaldehyde $(2 \mathrm{mmol})$, ammonium acetate $(3 \mathrm{mmol})$, and PANI-HEDP catalyst $(40 \mathrm{mg})$.

this work, our interest is the use of PANI-HEDP salt as novel polymer based solid acid catalyst in the one-pot condensation of aromatic aldehydes, ethyl acetoacetate, and ammonium acetate (Scheme 2).

In a typical procedure, the symmetrical Hantzsch reaction was carried out with ethyl acetoacetate $(4 \mathrm{mmol})$, 4-chlorobenzaldehyde $(2 \mathrm{mmol})$, and ammonium acetate (3 mmol) using PANI-HEDP catalyst ( $40 \mathrm{mg}, 7 \mathrm{wt} \%$ ) in $5 \mathrm{~mL}$ solvent at ambient temperature. Among the solvents used, acetonitrile solvent gave higher yield compared to that of dichloromethane and water (Table 1). In order to achieve greener process, the same reaction was carried out without any solvent and this reaction gave excellent yield (93\%) in short time $(10 \mathrm{~min})$. Product was not obtained when the reaction was carried out without catalyst even up to $1.5 \mathrm{~h}$.

In order to find out the versatility of this catalyst, the standard reaction under solvent free condition was further extended by changing the aromatic aldehydes and the results are reported in Table 2. In all the cases, the reaction proceeded smoothly to furnish the desired 1,4-dihydropyridine derivatives in $84-94 \%$ yields. Generally, electron-rich or electron-deficient aldehydes do not affect the yield of the product.

After successfully synthesizing a series of 1,4dihydropyridines in excellent yields under the optimized conditions, we turned our attention toward the synthesis of polyhydroquinoline derivatives via unsymmetrical Hantzsch reaction. We carried out the reaction with ethyl acetoacetate ( $2 \mathrm{mmol})$, dimedone (2 mmol), 4-chlorobenzaldehyde $(2 \mathrm{mmol})$, and ammonium acetate $(3 \mathrm{mmol})$ in presence 


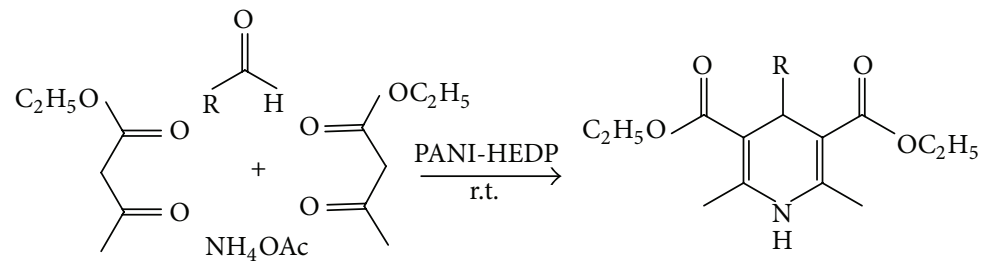

Scheme 2: Synthesis of 1,4-dihydropyridines using PANI-HEDP catalyst.<smiles>[R]C(=O)CC(=O)C1=C(C)NC2=C(C(=O)CC(C)(C)C2)C([R])C1C(=O)OCC</smiles>

Scheme 3: Synthesis of polyhydroquinolines using PANI-HEDP catalyst.

TABLE 2: PANI-HEDP catalyzed synthesis of 1,4-dihydropyridines under solvent free condition at ambient temperature ${ }^{\mathrm{a}}$.

\begin{tabular}{lccc}
\hline Entry & $\mathrm{R}$ & Time (min) & Isolated yield (\%) \\
\hline 1 & $\mathrm{Ph}$ & 10 & 93 \\
2 & $4-\mathrm{ClC}_{6} \mathrm{H}_{4}$ & 10 & 90 \\
3 & $4-\mathrm{BrC}_{6} \mathrm{H}_{4}$ & 20 & 86 \\
4 & $4-\mathrm{CH}_{3} \mathrm{C}_{6} \mathrm{H}_{4}$ & 15 & 94 \\
5 & $4-\mathrm{OCH}_{3} \mathrm{C}_{6} \mathrm{H}_{4}$ & 20 & 88 \\
6 & $2-\mathrm{ClC}_{6} \mathrm{H}_{4}$ & 20 & 90 \\
7 & $2-\mathrm{BrC}_{6} \mathrm{H}_{4}$ & 30 & 84 \\
8 & $2-\mathrm{CH}_{3} \mathrm{C}_{6} \mathrm{H}_{4}$ & 25 & 88 \\
\hline
\end{tabular}

${ }^{a}$ Ethyl acetoacetate $(4 \mathrm{mmol})$, 4-chlorobenzaldehyde $(2 \mathrm{mmol})$, ammonium acetate $(3 \mathrm{mmol})$, and PANI-HEDP catalyst $(40 \mathrm{mg})$.

TABLE 3: PANI-HEDP catalyzed synthesis of polyhydroquinolines under solvent free condition at ambient temperature ${ }^{\mathrm{a}}$.

\begin{tabular}{lccc}
\hline Entry & $\mathrm{R}$ & Time (min) & Isolated yield (\%) \\
\hline 1 & $\mathrm{Ph}$ & 15 & 89 \\
2 & $4-\mathrm{ClC}_{6} \mathrm{H}_{4}$ & 10 & 90 \\
3 & $4-\mathrm{BrC}_{6} \mathrm{H}_{4}$ & 25 & 87 \\
4 & $4-\mathrm{CH}_{3} \mathrm{C}_{6} \mathrm{H}_{4}$ & 15 & 92 \\
5 & $4-\mathrm{OHC}_{6} \mathrm{H}_{4}$ & 15 & 90 \\
6 & $2-\mathrm{ClC}_{6} \mathrm{H}_{4}$ & 20 & 86 \\
7 & $2-\mathrm{BrC}_{6} \mathrm{H}_{4}$ & 40 & 82 \\
8 & $2-\mathrm{CH}_{3} \mathrm{C}_{6} \mathrm{H}_{4}$ & 20 & 84 \\
\hline
\end{tabular}

${ }^{a}$ Ethylacetoacetate $(2 \mathrm{mmol})$, dimedone $(2 \mathrm{mmol})$, 4-chlorobenzaldehyde $(2 \mathrm{mmol})$, ammonium acetate $(3 \mathrm{mmol})$, and PANI-HEDP catalyst $(40 \mathrm{mg})$.

of PANI-HEDP catalyst (40 mg, $7 \mathrm{wt} \%$ ) under solvent free condition at room temperature (Scheme 3). The reaction was completed within $10 \mathrm{~min}$, and the product was obtained in excellent yields (Table 3).

Using the optimized reaction conditions, we synthesized a number of polyhydroquinoline derivatives. It is noteworthy that the nature of the substituents on the aromatic ring showed no obvious effect on this conversion, because they were obtained in high yields in relatively short reaction times.

Polyaniline salt contains repeated aniline backbones with protic acid group as dopant. This protic acid on polyaniline chain gives hydrogen ion easily during this organic reaction and acts as catalyst.

3.7. Recyclability. Reusability of the PANI-HEDP was verified for the standard reaction of ethyl acetoacetate, dimedone, 4-chlorobenzaldehyde, and ammonium acetate in the presence of PANI-HEDP catalyst under solvent free condition at room temperature for $10 \mathrm{~min}$. The reaction gave 1,4dihydropyridine in $93 \%$ yield. Catalyst was recovered by simple filtration, washed with acetone, dried at ambient temperature, and used for the next run. The yields of the product obtained in the subsequent cycles are 93, 90, 88, 89 , and $87 \%$. At the end of the recyclability experiments, the catalyst was isolated and analyzed by infrared, X-ray diffraction, FE-SEM, and TGA analyses. A similar result for the catalyst was observed before and after the recycling reaction (Figures 1-4). The above results indicate that PANIHEDP catalyst shows good recyclability.

\section{Conclusions}

In summary, nanospheres of polyaniline salt containing protic acid group with excellent yield in semicrystalline powder form were synthesized easily. Polyaniline powder is used as an efficient, easily handlable, versatile, reusable, and greener catalyst in the symmetrical and unsymmetrical Hantzsch reaction.

\section{Conflict of Interests}

The authors declare that there is no conflict of interests regarding the publication of this paper.

\section{Acknowledgments}

The authors thank Dr. Lakshmi Kantam, Director, and Dr. K.V.S.N. Raju, Head, PFM Division, IICT, for their support and encouragement. The authors thank CSIR in-house project (MLP-0006) for funding. Ravi and Rajender are indebted to UGC, India, for Senior Research Fellowship. 


\section{References}

[1] F. Bossert, H. Meyer, and E. Wehinger, "4-Aryldihydropyridines, a new class of highly active calcium antagonists," Angewandte Chemie, vol. 20, no. 9, pp. 762-769, 1981.

[2] H. Nakayama and Y. Kanaoka, "Chemical identification of binding sites for calcium channel antagonists," Heterocycles, vol. 42, no. 2, pp. 901-909, 1996.

[3] F. R. Buhler and W. J. Kiowski, "Calcium antagonists in hypertension,” Hypertension, vol. 5, no. 2, pp. S3-S10, 1987.

[4] J. L. Reid, P. A. Meredith, and F. Pasanisi, "Clinical pharmacological aspects of calcium antagonists and their therapeutic role in hypertension," Journal of Cardiovascular Pharmacology, vol. 7, no. 4, pp. S18-S20, 1985.

[5] M. Kawase, A. Shah, H. Gaveriya, N. Motohashi, H. Sakagami, and A. V. Molnar, "3,5-Dibenzoyl-1,4-dihydropyridines: synthesis and MDR reversal in tumor cells," Bioorganic and Medicinal Chemistry, vol. 10, no. 4, pp. 1051-1055, 2002.

[6] R. Mannhold, B. Jablonka, W. Voigt, K. Schonafinger, and E. Schraven, "Calcium- and calmodulin-antagonism of elnadipine derivatives: comparative SAR," European Journal of Medicinal Chemistry, vol. 27, no. 3, pp. 229-235, 1992.

[7] A. Hantzsch, "Ueber die Synthese pyridinartiger Verbindungen aus Acetessigäther und Aldehydammoniak," Justus Liebigs Annalen der Chemie, vol. 215, no. 1, pp. 1-82, 1882.

[8] G.-W. Wang, J.-J. Xia, C.-B. Miao, and X.-L. Wu, "Environmentally friendly and efficient synthesis of various 1,4dihydropyridines in pure water," Bulletin of the Chemical Society of Japan, vol. 79, no. 3, pp. 454-459, 2006.

[9] M. A. Zolfigol and M. Safaiee, "Synthesis of 1,4-dihydropyridines under solvent-free conditions," Synlett, no. 5, pp. 827-828, 2004.

[10] J. B. Sainani, A. C. Shah, and V. P. Arya, "Formation of 1 ,4,5,6,7,8 -Hexahydro-pyrido(4,3-b)pyridine by Hantzsch synthesis," Indian Journal of Chemestry B, vol. 33, pp. 526-531, 1994.

[11] M. Sufirez, E. Ochoa, Y. Verdecia et al., "A joint experimental and theoretical structural study of novel substituted 2,5-dioxo1,2,3,4,5,6,7,8-octahydroquinolines," Tetrahedron, vol. 55, no. 3 , pp. 875-884, 1999.

[12] N. N. Karade, V. H. Budhewar, S. V. Shinde, and W. N. Jadhav, "L-proline as an efficient organo-catalyst for the synthesis of polyhydroquinoline via multicomponent Hantzsch reaction," Letters in Organic Chemistry, vol. 4, no. 1, pp. 16-19, 2007.

[13] C. S. Reddy and M. Raghu, "Cerium(IV) ammonium nitrate catalysed facile and efficient synthesis of polyhydroquinoline derivatives through Hantzsch multicomponent condensation," Chinese Chemical Letters, vol. 19, no. 7, pp. 775-779, 2008.

[14] M. Maheswara, V. Siddaiah, G. L. V. Damu, and C. V. Rao, “An efficient one-pot synthesis of polyhydroquinoline derivatives via Hantzsch condensation using a heterogeneous catalyst under solvent-free conditions," Arkivoc, vol. 2006, no. 2, pp. 201206, 2006.

[15] S. B. Sapkal, K. F. Shelke, B. B. Shingate, and M. S. Shingare, "Nickel nanoparticle-catalyzed facile and efficient one-pot synthesis of polyhydroquinoline derivatives via Hantzsch condensation under solvent-free conditions," Tetrahedron Letters, vol. 50, no. 15, pp. 1754-1756, 2009.

[16] R. Surasani, D. Kalita, A. V. D. Rao, K. Yarbagi, and K. B. Chandrasekhar, " $\mathrm{FeF}_{3}$ as a novel catalyst for the synthesis of polyhydroquinoline derivatives via unsymmetrical Hantzsch reaction," Journal of Fluorine Chemistry, vol. 135, pp. 91-96, 2012.
[17] M. M. Heravi, K. Bakhtiari, N. M. Javadi, F. F. Bamoharram, M. Saeedi, and H. A. Oskooie, " $\mathrm{K}_{7}\left[\mathrm{PW}_{11} \mathrm{CoO}_{40}\right]$-catalyzed one-pot synthesis of polyhydroquinoline derivatives via the Hantzsch three component condensation," Journal of Molecular Catalysis A: Chemical, vol. 264, no. 1-2, pp. 50-52, 2007.

[18] R. A. Mekheimer, A. A. Hameed, and K. U. Sadek, "Solar thermochemical reactions: four-component synthesis of polyhydroquinoline derivatives induced by solar thermal energy," Green Chemistry, vol. 10, no. 5, pp. 592-593, 2008.

[19] A. Kumar and R. A. Maurya, "Bakers' yeast catalyzed synthesis of polyhydroquinoline derivatives via an unsymmetrical Hantzsch reaction," Tetrahedron Letters, vol. 48, no. 22, pp. 3887-3890, 2007.

[20] M. Kidwai, R. Chauhan, D. Bhatnagar, A. K. Singh, B. Mishra, and S. Dey, "Nafion-H-catalyzed synthesis of polyhydroquinolines via the Hantzsch multicomponent reaction," Monatshefte fur Chemie, vol. 143, no. 12, pp. 1675-1680, 2012.

[21] M. Y. Masoomi and A. Morsali, "Applications of metal-organic coordination polymers as precursors for preparation of nanomaterials," Coordination Chemistry Reviews, vol. 256, no. 23-24, pp. 2921-2943, 2012.

[22] M. Y. Masoomi and A. Morsali, "Morphological study and potential applications of nano metal-organic coordination polymers," RSC Advances, vol. 3, no. 42, pp. 19191-19218, 2013.

[23] M. Y. Masoomi, K. C. Stylianou, A. Morsali, P. Retailleau, and D. Maspoch, "Selective $\mathrm{CO}_{2}$ capture in metal-organic frameworks with azine-functionalized pores generated by mechanosynthesis," Crystal Growth and Design, vol. 14, no. 5, pp. 2092-2096, 2014.

[24] S. Palaniappan, B. Rajender, and M. Umashankar, "Controllable stereoselective synthesis of cis or trans pyrano and furano tetrahydroquinolines: polyaniline-p-toluenesulfonate salt catalyzed one-pot aza-Diels-Alder reactions," Journal of Molecular Catalysis A: Chemical, vol. 352, pp. 70-74, 2012.

[25] S. Palaniappan and A. John, "Conjugated polymers as heterogeneous catalyst in organic synthesis," Current Organic Chemistry, vol. 12 , no. 2, pp. 98-117, 2008. 

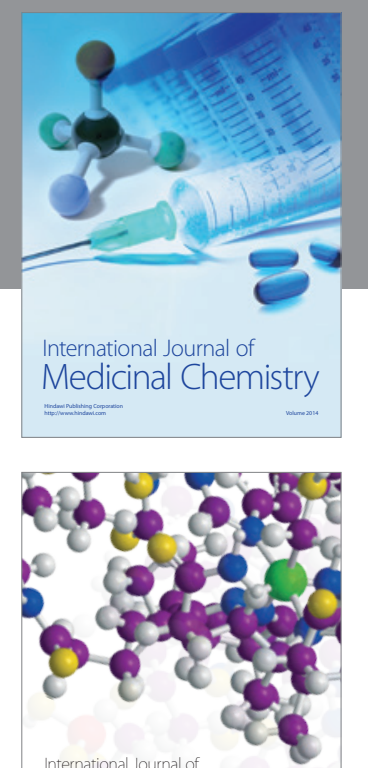

\section{Carbohydrate} Chemistry

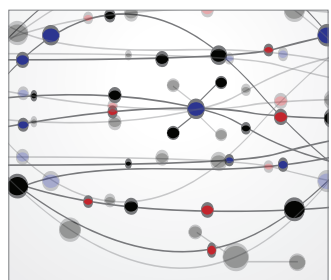

The Scientific World Journal
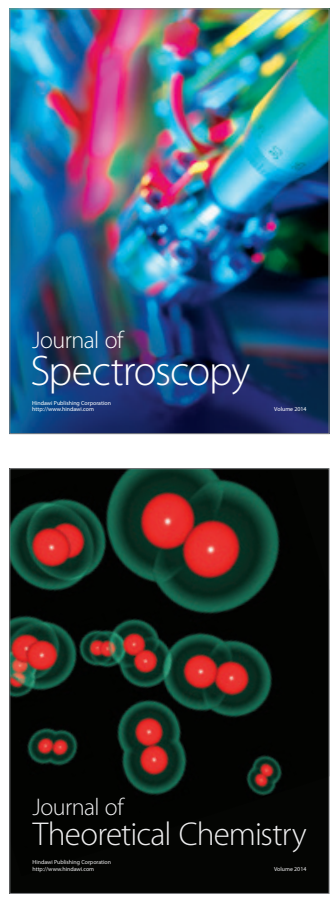
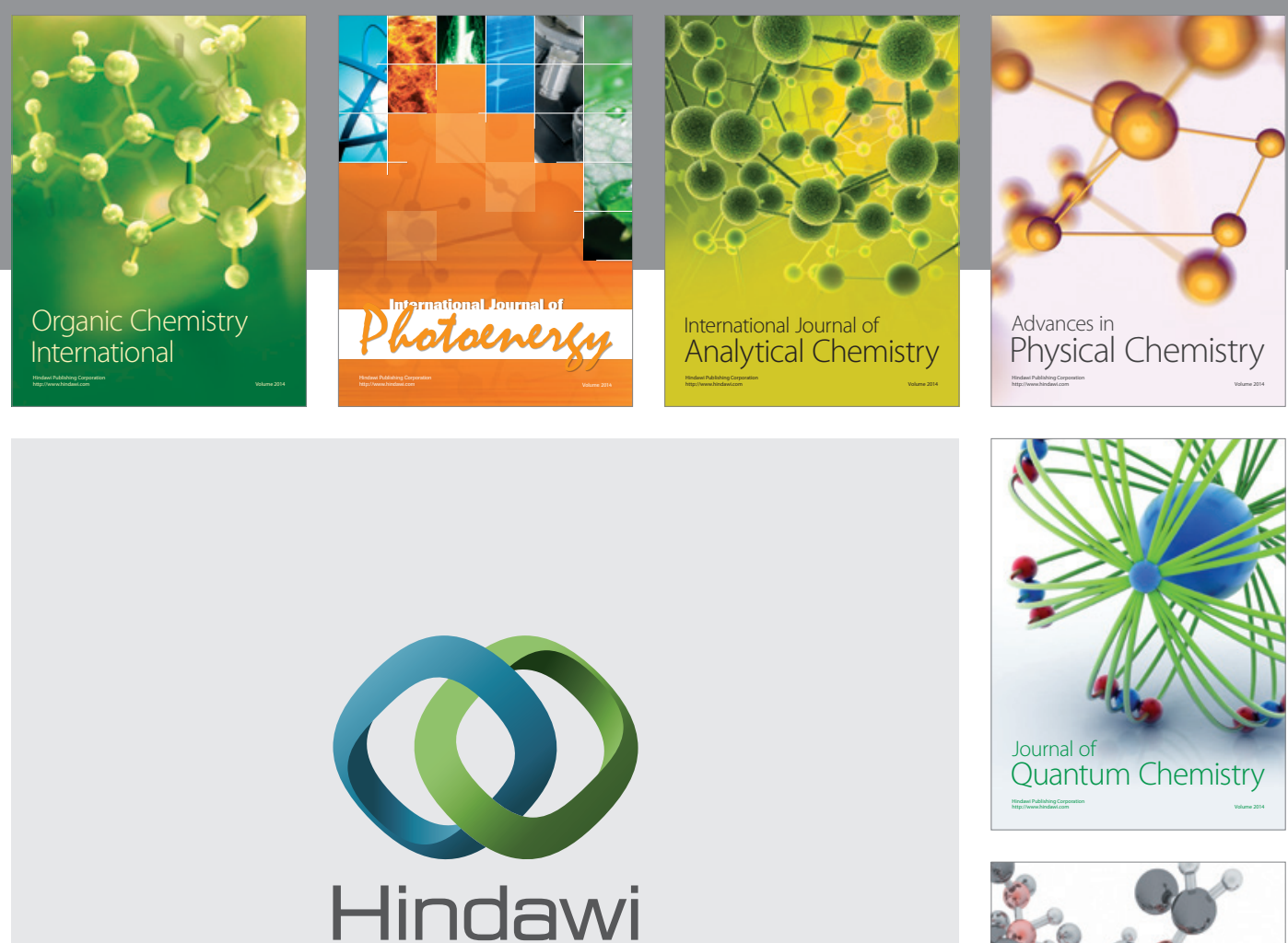

Submit your manuscripts at

http://www.hindawi.com

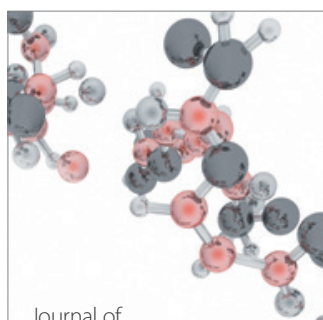

Analytical Methods

in Chemistry

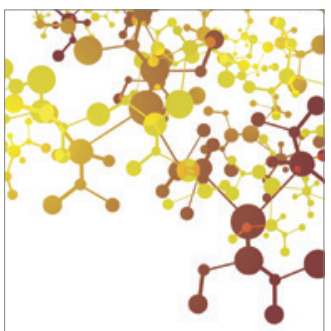

Journal of

Applied Chemistry

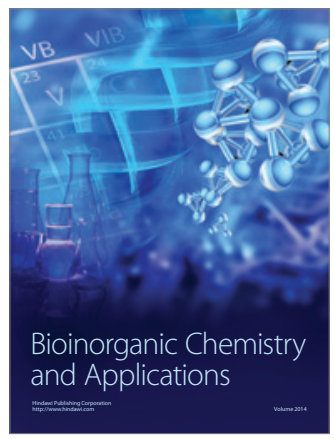

Inorganic Chemistry
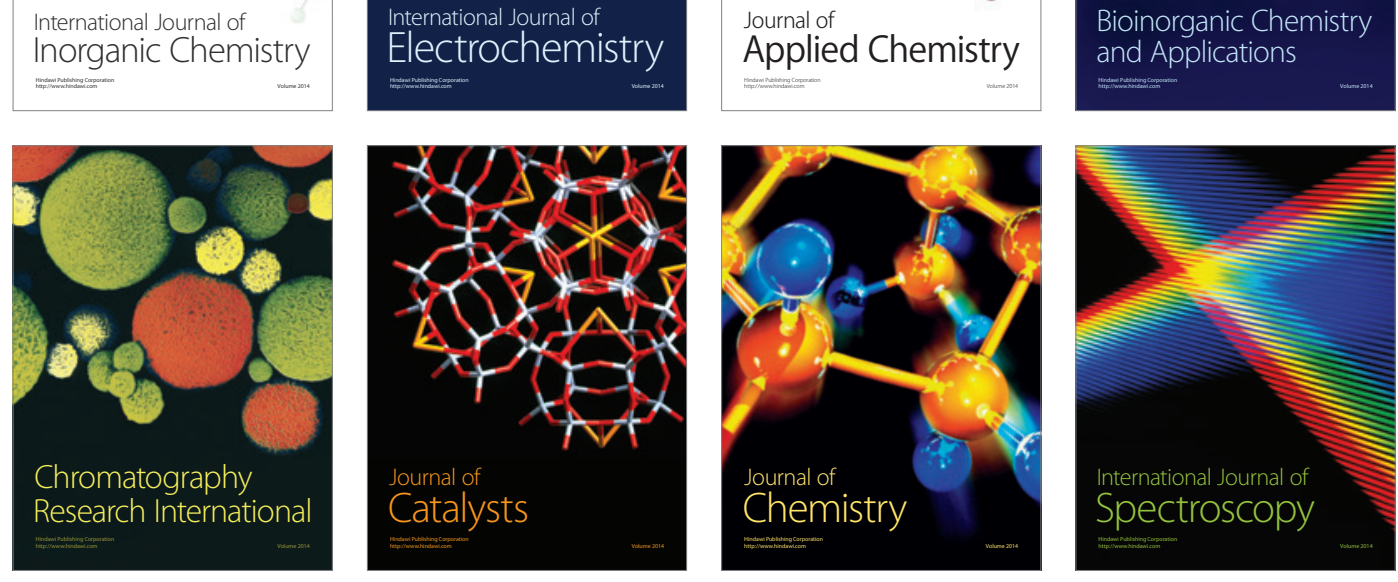